\title{
PENGARUH INFORMATION QUALITY DAN RELATIONSHIP QUALITY TERHADAP UNCERTAINTY REDUCTION DAN PURCHASE INTENTION
}

\author{
Melinda Ika Sari ${ }^{1}$, Keni $^{2}$ \\ ${ }^{1}$ Program Studi Magister Manajemen Universitas Tarumanagara Jakarta \\ Email: melindaikasari@gmail.com \\ ${ }^{2}$ Fakultas Ekonomi, Universitas Tarumanagara Jakarta \\ ${ }^{2}$ Program Studi Magister Manajemen Universitas Tarumanagara Jakarta \\ Email: keni@fe.untar.ac.id
}

Masuk : 15-04-2019, revisi: 11-08-2019, diterima untuk diterbitkan : 11-08-2019

\begin{abstract}
ABSTRAK
Penelitian ini bertujuan untuk menganalisis pengaruh parsial information quality dan relationship quality dalam komunitas online terhadap uncertainty reduction, pengaruh uncertainty reduction terhadap purchase intention, dan pengaruh involvement terhadap hubungan uncertainty reduction dan purchase intention. Subyek penelitian ini adalah orang-orang yang sudah pernah menggunakan salah satu dari komunitas online Youtube, Kompas Tekno, atau Tabloit PULSA untuk mencari informasi mengenai smartphone. Metode pengambilan sampel dilakukan dengan metode non probability sampling dengan teknik pengambilan sampel adalah convenience sampling dengan metode penyebaran kuisioner secara online. Total sampel yang terkumpul ada 159 sampel. Penelitian ini menggunakan dua analisis regresi, yaitu: analisis regresi linier ganda dan moderated regression analysis. Hasil dari penelitian ini adalah secara parsial information quality dan relationship quality memiliki pengaruh positif dan signifikan terhadap uncertainty reduction. Sementara itu, uncertainty reduction memberikan pengaruh yang positif dan signifikan terhadap purchase intention. Involvement sebagai moderator tidak memberikan pengaruh pada hubungan uncertainty reduction dan purchase intention.
\end{abstract}

Kata Kunci: purchase intention, uncertainty reduction, information quality, relationship quality, involvement

\begin{abstract}
This study aims to analyze the partial influence of information quality and relationship quality in the online community on uncertainty reduction, the influence of uncertainty reduction on purchase intention, and the influence of involvement on the relationship of uncertainty reduction and purchase intention. The subjects of this study were people who had used one of the online communities: Youtube, Kompas Tekno, or TabloitPULSA to find information about smartphones. This study is using non probability sampling method with convenience sampling as a sampling technique and online questionnaire as a distribution method. The total samples collected were 159 samples. This study used two regression analyses: multiple linear regression analysis and moderated regression analysis. The results of this study are that information quality and relationship quality partially has a positive and significant influence on uncertainty reduction. Meanwhile, uncertainty reduction has a positive and significant influence on purchase intention. Involvement as a moderator has no effect on the relationship of uncertainty reduction and purchase intention.
\end{abstract}

Keywords: purchase intention, uncertainty reduction, information quality, relationship quality, involvement

\section{PENDAHULUAN}

\section{Latar Belakang}

Indonesia merupakan salah satu target pasar penjualan smartphone terbesar di dunia karena jumlah penduduknya yang besar dan memiliki kecenderungan untuk berbelanja. Besarnya pasar smartphone Indonesia merupakan peluang yang baik bagi para perusahaan smartphone untuk menjual produknya di Indonesia. Pada kuartal 2 di tahun 2018, terjadi persaingan market share smartphone yang cukup ketat antar brand smartphone (Statista.com, 2018). 
Purchase intention merupakan suatu dorongan yang dapat menstimulasi dan mengendalikan konsumen sehingga terjadi pembelian produk atau jasa. Purchase intention akan muncul setelah seorang calon konsumen melakukan evaluasi terhadap suatu produk atau jasa (Kotler \& Armstrong, 2012). Purchase intention sendiri dapat dipengaruhi oleh beberapa faktor. Dengan mempelajari faktor yang mempengaruhi purchase intention, maka dapat membantu produsen dalam memenuhi keinginan konsumen. Selain itu, dengan mempelajari faktor-faktor yang mempengaruhi purchase intention, maka dapat memperkuat hubungan produsen dengan konsumen sehingga tercipta hubungan yang menguntungkan bagi kedua pihak (Mirabi, Akbariyeh, \& Tahmasebifard, 2015).

Terdapat beberapa penelitian terdahulu yang meneliti mengenai purchase intention. Wang, Lee, $\mathrm{Wu}$, dan Liu (2017) menyebutkan bahwa purchase intention dapat dipengaruhi oleh banyak faktor, salah satunya yaitu uncertainty reduction. Selain itu, terdapat faktor lain yang mempengaruhi hubungan uncertainty reduction dan purchase intention, yaitu involvement. Sementara itu, faktor yang mempengaruhi uncertainty reduction adalah information quality dan relationship quality dalam sebuah komunitas online. Komunitas ini termasuk sebagai media yang efektif dalam memfasilitasi konsumen untuk saling berkomunikasi.

Sementara itu, penelitian yang dilakukan oleh Elliot, Li, dan Choi (2012) menunjukkan kaitan variabel information quality, satisfaction, trust, dan purchase intention. Information quality memiliki pengaruh positif terhadap satisfaction dan trust yang merupakan komponen dari relationship quality dalam suatu komunitas online. Pada penelitian ini, trust tidak berpengaruh secara langsung terhadap purchase intention, sedangkan satisfaction berpengaruh secara tidak langsung terhadap purchase intention melalui site stickiness.

Adjei, Noble, dan Noble (2010) melakukan penelitian yang menunjukkan bahwa kualitas komunikasi akan berpengaruh positif terhadap uncertainty reduction dan purchase intention. Selain itu, penelitian ini juga menjelaskan efek uncertainty reduction sebagai mediator yang memberikan pengaruh positif pada hubungan kualitas komunikasi dengan purchase intention. Penelitian yang dilakukan oleh Pavlou, Liang, dan Xue (2007) menunjukkan perceived uncertainty berpengaruh negatif terhadap purchase intention, sedangkan purchase involvement memberikan efek moderasi yang positif terhadap hubungan perceived uncertain dan purchase intention.

Penelitian ini dilakukan dengan tujuan untuk menganalisis pengaruh information quality dan relationship quality dalam komunitas online terhadap uncertainty reduction individu. Selain itu, untuk menganalisis pengaruh uncertainty reduction dalam komunitas online terhadap purchase intention, serta menganalisis pengaruh involvement dalam hubungan uncertainty reduction pada komunitas online terhadap purchase intention. Hasil penelitian ini diharapkan dapat memberikan kontribusi kepada perusahaan untuk mengetahui variabel yang berpengaruh terhadap uncertainty reduction dan purchase intention.

\section{Telaah Kepustakaan}

\section{Information quality}

Information quality menurut Miller (1996: 79) adalah "The meaning of information quality lies in how the information is perceived and used by its customer." Selain itu, information quality menurut Kinney (2000) dalam Azemi, Zaidi, dan Hussin (2017: 430) adalah sebagai berikut: 
"information quality as degree to which (a) Measurement methods used to prepare information can represent what a decision maker wants to know (information relevance) and (b) The stated methods have been competently applied and results truthfully displayed (information reliability or credibility)." Lebih lanjut Lillrank (2003: 698) menjelaskan information quality: "The producer of information has an intention to produce a symbolic representation of certain entities or events, put it into a context, assign it a pre-defined meaning and transmit it to a receiver. The expectation is that the receiver will capture the meaning as intended."

Dari kutipan di atas dapat didefinisikan bahwa information quality adalah suatu ukuran keberhasilan penerimaan informasi oleh penerima pesan sesuai dengan intensi pengiriman pesan oleh pengirim pesan dengan ekspektasi, penerima pesan akan mengerti maksud dari pengirim pesan.

\section{Relationship quality}

Definisi relationship quality menurut Hennig-Thurau dan Klee (1997: 751) adalah "the degree of appropriateness of a relationship to fulfill the needs of the customers associated with that relationship". Berdasarkan Palmatier, Dant, Grewal, dan Evans (2006: 138), relationship quality adalah "Overall assessment of the strength of a relationship, conceptualized as a composite or multidimensional construct capturing the different but related facets of a relationship". Sementara itu, relationship quality, menurut Morry, Reich, dan Kito (2010: 372) adalah "... how positive or negative individuals feel about their relationship".

Dari definisi yang sudah disebutkan, maka relationship quality, bila dihubungkan dengan komunitas online dapat didefinisikan sebagai suatu ukuran yang menunjukkan kekuatan hubungan yang terjalin antara konsumen dan perusahaan.

\section{Uncertainty reduction}

Menurut Pfeffer dan Salancik (1978) dalam Zhu, Chang, dan Chang (2015: 691), uncertainty adalah "the degree to which the future states of the environment cannot be accurately anticipated or predicted because of imperfect". Definisi uncertainty menurut Adjei et al. (2010: 635) adalah "the degree of confidence that a customer has in his or her ability to make predictions about the firm he or she is dealing with", sedangkan menurut Shiu, Walsh, Hassan, dan Shaw (2011: 585), uncertainty konsumen dapat didefinisikan sebagai "a condition where the information available deviates from the consumer's ideal information state".

Sementara itu, uncertainty reduction dapat didefinikan sebagai "the extent to which individuals report valuing complete knowledge of outcomes before engaging in actions" (Furner, Racherla, \& Zhu, 2012: 267). Dari semua definisi yang sudah disebutkan, uncertainty reduction pada penelitian ini dapat didefinisikan sebagai suatu keyakinan seseorang terhadap produk yang akan dibeli.

\section{Involvement}

Menurut Wang et al. (2017: 1988), involvement dapat diasosiasikan dengan "the level of perceived personal relevance or importance of a specific product category to the customer". Selain itu, menurut Huang (2012: 259), involvement adalah "a motivational state that affects the extent and focus of consumers' attention and comprehension processes as well as overt 
behaviors, such as shopping and consumption activities". Involvement menurut Venkatraman (1989: 230) adalah "the degree to which a consumer is motivated to avoid the negative outcomes of product purchase, therefore it captures a consumer's concern with avoiding a bad buy or making a sub-optimal choice".

Berdasarkan definisi yang sudah disebutkan, maka pada penelitian ini involvement didefinisikan sebagai suatu ukuran dimana konsumen berperan dalam proses pembelian produk untuk menghindari melakukan transaksi produk/servis yang buruk.

\section{Purchase intention}

Purchase intention menurut Morinez et al. (2007) dalam Mirabi, Akbariyeh, dan Tahmasebifard (2015: 268) adalah "a situation where consumer tends to buy a certain product in certain condition". Liat dan Wuan (2014: 122) mendefinisikan online purchase intention sebagai " $a$ situation when a person desires to buy a particular product or service through the website". Menurut Schiffman dan Kanuk (2014) dalam Tanjungsari dan Lunardy (2016: 264), "purchase intention dapat mengukur kemungkinan konsumen membeli suatu produk, dan semakin tinggi purchase intention yang dimiliki seseorang maka semakin tinggi kesediaannya untuk membeli produk". Dari definisi yang sudah disebutkan, maka pada penelitian ini, purchase intention didefinisikan sebagai suatu keinginan seseorang untuk melakukan transaksi.

\section{Kaitan antara information quality dan uncertainty reduction}

Information quality dalam suatu komunitas mempengaruhi secara signifikan terhadap kepercayaan dan kepuasan anggotanya, dan akhirnya akan mendorong intensi terjadinya transaksi (Elliot et al., 2013). Selain itu, dimensi information quality, seperti relevansi, frekuensi, durasi, dan timeliness berpengaruh positif terhadap uncertainty reduction (Adjei et al., 2010). Review dalam sebuah komunitas online dapat mempengaruhi uncertainty reduction. Kualitas review yang tinggi dapat meningkatkan uncertainty reduction sehingga semakin memperkuat purchase intention (Lee \& Shin, 2014). Lebih lanjut, hasil penelitian Wang et al. (2017) menunjukkan bahwa information quality memberikan pengaruh positif terhadap uncertainty reduction. Berdasarkan uraian di atas, hipotesis penelitian $\left(\mathrm{H}_{1}\right)$ adalah:

$\mathrm{H}_{1}$ : Terdapat pengaruh positif information quality dalam komunitas online terhadap uncertainty reduction individu.

\section{Kaitan antara relationship quality dan uncertainty reduction}

Relationship quality dalam suatu komunitas online terdiri dari tiga komponen, yaitu komitmen, kepuasan, dan kepercayaan. Kepercayaan dan kepuasan konsumen dalam sebuah komunitas online berpengaruh positif terhadap purchase intention melalui brand attitude dan site stickiness. Tingkat kepercayaan konsumen yang tinggi akan membantu menciptakan nilai positif brand yang dapat mengurangi uncertainty konsumen sehingga transaksi dapat terjadi. Sama halnya dengan kepuasan konsumen, di dalam suatu komunitas online, konsumen yang merasa puas akan lebih banyak menghabiskan waktu di komunitas online tersebut. Konsumen akan semakin banyak membaca ulasan, dan semakin banyak berkomunikasi dengan konsumen lainnya sehingga uncertainty yang ada dapat berkurang. Konsumen yang menghabiskan waktu yang lama di dalam suatu komunitas online dapat disebut sebagai konsumen yang memiliki site stickiness yang tinggi dan hal ini dapat meningkatkan kemungkinan terjadinya transaksi (Elliot et al., 2013). Dengan demikian dapat dikatakan bahwa relationship quality dapat meningkatkan 
uncertainty reduction sehingga mendorong timbulnya purchase intention. Berdasarkan uraian di atas, hipotesis penelitian $\left(\mathrm{H}_{2}\right)$ adalah:

$\mathrm{H}_{2}$ : Terdapat pengaruh positif relationship quality dalam komunitas online terhadap uncertainty reduction individu.

\section{Kaitan antara uncertainty reduction dan purchase intention}

Uncertainty reduction dalam komunitas online memiliki peran yang penting dalam mendorong terjadinya transaksi online. Uncertainty reduction memberikan efek positif pada purchase intention (Adjei et al., 2010; Wang et al., 2017). Penelitian yang dilakukan oleh Ma (2017) menunjukkan bahwa variabel uncertainty memberikan efek negatif pada purchase intention. Variabel uncertainty memiliki arti yang berlawanan dengan uncertainty reduction sehingga dapat dikatakan bahwa uncertainty reduction memberikan pengaruh positif pada purchase intention. Berdasarkan uraian di atas, hipotesis penelitian $\left(\mathrm{H}_{3}\right)$ adalah:

$\mathrm{H}_{3}$ : Terdapat pengaruh positif uncertainty reduction individu terhadap purchase intention.

\section{Kaitan antara uncertainty reduction dan purchase intention yang dimoderasi oleh involvement}

Peran dari involvement dalam memoderasi hubungan antara uncertainty reduction dan purchase intention telah diteliti oleh Pavlou, Liang, dan Xue (2007). Hasil penelitiannya menunjukkan bahwa semakin besar purchase involvement, maka akan semakin kuat hubungan perceived uncertainty reduction dengan purchase intention. Demikian juga dengan penelitian Wang et al. (2017) yang menunjukkan bahwa semakin besar efek moderasi dari involvement maka akan semakin besar pengaruh uncertainty reduction terhadap purchase intention. Berdasarkan uraian di atas, hipotesis penelitian $\left(\mathrm{H}_{4}\right)$ adalah:

$\mathrm{H}_{4}$ : Involvement dapat memoderasi secara positif pengaruh uncertainty reduction individu terhadap purchase intention.

Berdasarkan kaitan-kaitan yang telah diuraikan di atas, maka model penelitian dalam penelitian ini adalah sebagai berikut:

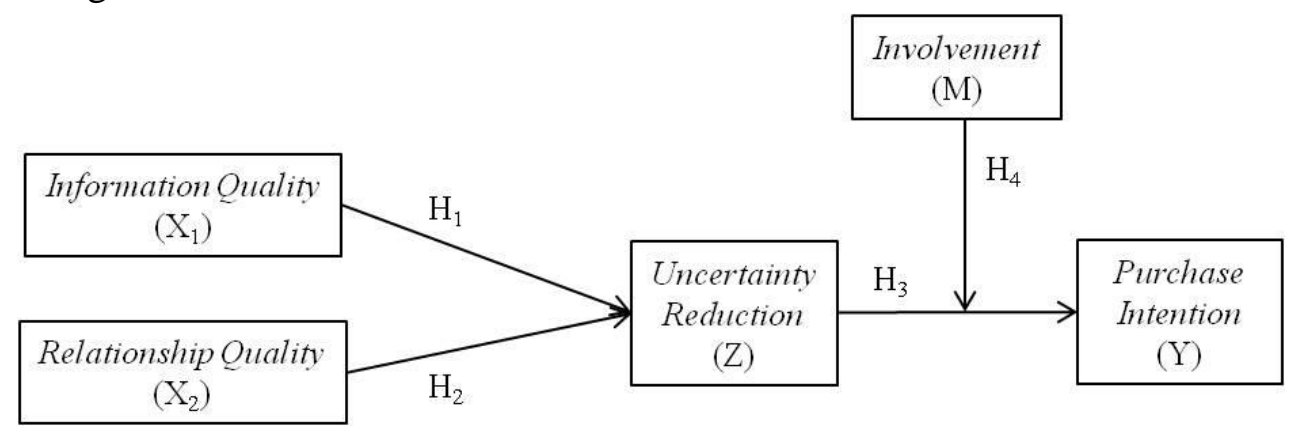

Gambar 1. Model penelitian

\section{METODE PENELITIAN}

Jenis penelitian ini adalah penelitian deskriptif. Sumber data yang digunakan adalah data primer. Penelitian ini dilakukan dengan menyebarkan kuisioner secara online dengan menggunakan Google Form. Data yang dihasilkan merupakan data cross section. Kuisioner berisi 23 butir pernyataan (Tabel 1.) untuk mengukur variabel information quality, relationship quality, uncertainty reduction, involvement, dan purchase intention dengan skala pengukuran Likert 5 
poin (1 menunjukkan sangat tidak setuju, dan 5 menunjukkan sangat setuju). Metode pengambilan sampel adalah metode non-probability sampling dengan teknik convenience sampling dengan ketentuan reesponden pernah menggunakan minimal salah satu dari tiga komunitas online Youtube, atau KompasTekno, atau TabloitPULSA untuk mencari informasi mengenai smartphone. Data yang terkumpul sebanyak 159 orang yang sebagian besar berjenis kelamin pria $(51,6 \%)$, berusia $21-30$ tahun $(79,9 \%)$, bekerja sebagai karyawan $(76,1 \%)$ dengan lokasi domisili di Jakarta $(60,4 \%)$.

Tabel 1. Variabel dan pengukuran

\begin{tabular}{lcl}
\hline Variabel & Item & \multicolumn{1}{c}{ Sumber } \\
\hline Information quality & 5 & Wang et al. (2017); Ahn, Ryu, dan Han (2007) \\
\hline Relationship quality & 6 & Wang et al. (2017); Hennig-Thurau, Gwinner, dan Gremler (2002) \\
\hline Uncertainty reduction & 3 & Wang et al. (2017) \\
\hline Involvement & 5 & $\begin{array}{l}\text { Wang } \text { et al. (2017); Kim, Kim, dan Park (2010); Rahman, Albaity, } \\
\text { Isa, dan Azma (2018) }\end{array}$ \\
\hline Purchase intention & 4 & Wang et al. (2017); Barber dan Taylor (2013) \\
\hline
\end{tabular}

Hasil analisis validitas menunjukkan nilai corrected item-total correlation berkisar dari 0,577 sampai 0,878 lebih besar daripada $r$ tabel sebesar 0.1557 sehingga semua butir pernyataan dalam instrumen adalah valid (Ghozali, 2016). Sementara itu, analisis reliabilitas menunjukkan semua variabel penelitian memiliki nilai Cronbach's Alpha berkisar 0,806 sampai 0,910 lebih besar daripada 0,60 sehingga semua variabel penelitian reliabel (Ghozali, 2016). Hasil analisis validitas, reliabilitas dan teknik analisis data dilakukan dengan bantuan program software SPSS.

Setelah itu, uji asumsi klasik dilakukan untuk melihat apakah persamaan regresi terbebas dari masalah asumsi klasik. Penelitian ini menggunakan 2 analisis regresi, yaitu: 1. analisis regresi linier ganda untuk mengetahui adanya hubungan variabel dependen terhadap variabel independen, 2. moderated regression analysis (MRA) untuk mengetahui ada tidaknya pengaruh moderasi dalam suatu hubungan. Uji asumsi klasik yang dilakukan adalah uji normalitas (kedua model regresi menghasilkan residual data berdistribusi normal), uji heteroskedastisitas (kedua model regresi tidak terjadi heteroskedastisitas), dan uji multikolinieritas (pada model regresi linier ganda tidak terjadi multikolinieritas).

\section{HASIL DAN PEMBAHASAN}

Hasil uji asumsi klasik menunjukkan bahwa kedua model regresi dapat digunakan untuk menganalisis data karena terbebas dari masalah asumsi klasik. Persamaan regresi linier berganda adalah $\mathrm{Z}=1.203+0.456 \mathrm{X}_{1}+0.186 \mathrm{X}_{2}$, sedangkan persamaan MRA adalah $\mathrm{Y}=-0.196+0.821$ $\mathrm{Z}+0.309 \mathrm{M}+0.018 \mathrm{Z} * \mathrm{M}$. Dari kedua persamaan tersebut terlihat bahwa information quality lebih mempengaruhi uncertainty reduction dibandingkan dengan relationship quality. Selain itu, uncertainty reduction merupakan variabel yang paling besar mempengaruhi purchase intention dan adanya involvement memberikan pengaruh positif terhadap hubungan uncertainty reduction dan purchase intention. Hasil penelitian ini dapat dilihat pada Tabel 2 dan Tabel 3. 
Tabel 2. Analisis regresi linier ganda

\begin{tabular}{|c|c|c|c|}
\hline \multicolumn{2}{|r|}{ Hipotesis } & \multirow{2}{*}{$\begin{array}{c}\text { Koefisien } \\
0.456\end{array}$} & \multirow{2}{*}{$\begin{array}{c}\text { Nilai t } \\
7.173 * * *\end{array}$} \\
\hline $\mathrm{H}_{1}$ & Information quality $\rightarrow$ uncertainty reduction & & \\
\hline $\mathrm{H}_{2}$ & Relationship quality $\rightarrow$ uncertainty reduction & 0.186 & $2.960 * *$ \\
\hline
\end{tabular}

Hasil pengujian hipotesis $\mathrm{H}_{1}$ tidak ditolak, artinya, terdapat pengaruh positif information quality dalam komunitas online terhadap uncertainty reduction individu. Hasil ini sama dengan hasil penelitian yang dilakukan oleh Wang et al. (2017), Elliot et al. (2012), serta Adjei et al. (2010). Information quality yang terdiri dari timeliness, relevansi, kelengkapan, akurasi, dan tingkat kepercayaan informasi merupakan variabel yang penting dalam menentukan purchase intention konsumen melalui uncertainty reduction. Information quality mempengaruhi kepercayaan dan kepuasan anggotanya sehingga mendorong intensi terjadinya transaksi (Elliot et al., 2012).

Tabel 3. Moderated regression analysis

\begin{tabular}{cccc}
\hline & Hipotesis & Koefisien & Nilai t \\
\hline $\mathrm{H}_{3}$ & Uncertainty reduction $\rightarrow$ purchase intention & 0.821 & $4,322^{* * *}$ \\
\hline \multicolumn{2}{c}{ Involvement $\rightarrow$ purchase intention } & 0.309 & 1.526 \\
\hline $\mathrm{H}_{4}$ & $\begin{array}{c}\text { Involvement pada uncertainty reduction } \rightarrow \\
\text { purchase intention }\end{array}$ & 0.018 & -0.342 \\
\hline
\end{tabular}

*pada taraf signifikansi $0.05, * *$ pada taraf signifikansi $0.01, * * *$ pada taraf signifikansi 0.001

Sementara hasil pengujian hipotesis menunjukkan $\mathrm{H}_{2}$ tidak ditolak, artinya, terdapat pengaruh positif relationship quality dalam komunitas online terhadap uncertainty reduction individu. Hasil ini sama dengan hasil penelitian yang dilakukan oleh Wang et al. (2017) dan Elliot et al. (2012). Relationship quality yang terdiri dari kepuasan, kepercayaan, dan komitmen dalam suatu komunitas online memiliki pengaruh yang positif terhadap uncertainty reduction. Relationship quality yang besar dalam suatu komunitas online dapat mendorong orang untuk mencari informasi akan suatu produk di komunitas online tersebut dan pada akhirnya menjadi yakin akan produk tersebut. Keyakinan ini yang akan mendorong terjadinya purchase intention.

Hasil pengujian hipotesis $\mathrm{H}_{3}$ tidak ditolak. Artinya, terdapat pengaruh positif uncertainty reduction individu terhadap purchase intention. Hasil ini sama dengan hasil penelitian yang dilakukan oleh Wang et al. (2017) dan Adjei et al. (2010). Uncertainty reduction merupakan variabel yang penting dalam mendorong timbulnya purchase intention. Keraguan konsumen pada saat akan membeli suatu produk dapat menurunkan jumlah transaksi yang terjadi. Oleh sebab itu, perusahaan yang menjual produk harus selalu mencari cara agar keraguan ini dapat berkurang atau bahkan menghilang sehingga kemungkinan transaksi dapat meningkat. Caranya adalah dengan membuat strategi pemasaran yang dapat meyakinkan konsumen sehingga semua keraguan konsumen dapat berkurang dan purchase intention dapat muncul.

Hasil pengujian hipotesis $\mathrm{H}_{4}$ ditolak dikarenakan hasil analisisnya tidak signifikan. Hal ini menunjukkan bahwa involvement tidak memoderasi secara positif dan signifikan pengaruh uncertainty reduction individu terhadap purchase intention. Hasil ini tidak sama dengan hasil penelitian yang dilakukan oleh Wang et al. (2017) dan Pavlou et al. (2007). Involvement adalah 
bentuk tindakan pencegahan agar konsumen tidak membeli produk yang buruk. Pada umumnya, involvement dilakukan oleh konsumen pada saat akan membeli produk-produk yang kompleks dengan harga yang mahal. Smartphone pada hakikatnya merupakan produk kompleks yang memiliki harga mahal. Akan tetapi, saat ini sudah banyak smartphone dengan harga murah (low end) sehingga tingkat involvement konsumen pada saat akan membeli smartphone menjadi berkurang.

Berdasarkan hasil penelitian di atas ditemukan bahwa information quality dan relationship quality memiliki pengaruh yang positif terhadap uncertainty reduction konsumen. Uncertainty reduction memiliki pengaruh yang positif terhadap purchase intention dalam produk smartphone. Involvement tidak berpengaruh secara signifikan terhadap hubungan uncertainty reduction dan purchase intention produk smartphone. Dengan demikian, perusahaan dapat memanfaatkan komunitas online sebagai media pemasaran yang efektif untuk menyakinkan konsumen untuk melakukan pembelian.

\section{KESIMPULAN DAN SARAN}

Kesimpulan dari penelitian ini adalah bahwa secara parsial information quality dan relationship quality pada komunitas online memberikan pengaruh yang positif dan signifikan terhadap uncertainty reduction. Uncertainty reduction mendorong terjadi purchase intention. Involvement tidak mempengaruhi hubungan uncertainty reduction dengan purchase intention pada saat pencarian informasi.

Peneliti menyarankan bagi perusahaan untuk membuat rencana pemasaran dengan melibatkan komunitas online sebagai media pemasarannya. Pemilihan komunitas online yang akan digunakan sebagai media pemasaran perlu mempertimbangkan aspek kualitas informasi dan kualitas hubungan anggota dengan komunitas online karena aspek tersebut dianggap penting oleh konsumen dan dapat memperbesar uncertainty reduction dari produk yang akan dipasarkan.

Penelitian ini hanya meneliti variabel information quality dan relationship quality terhadap uncertainty reduction, serta uncertainty reduction dan involvement sebagai moderator terhadap purchase intention. Bagi penelitian selanjutnya, diharapkan dapat melakukan penelitian dengan faktor-faktor yang mempengaruhi purchase intention lainnya seperti customer value, persepsi kualitas perusahaan, dan strategi pemasaran perusahaan. penelitian ini hanya meneliti purchase intention bukan pembelian yang sebenarnya. Dari tahapan purchase intention menuju ke purchase decision terdapat dua faktor yang dapat mempengaruhi purchase intention barang A berubah menjadi purchase decision barang $\mathrm{B}$. Faktor tersebut adalah attitude of other dan unexpected situational factor (Kotler \& Armstrong, 2012). Oleh karena itu, diperlukannya penelitian dalam skala besar dengan variabel dependent purchase decision agar tujuan akhir pemasaran, yaitu terjadi transaksi dapat semakin dimengerti dan dipahami.

\section{Ucapan Terima Kasih}

Penulis mengucapkan terima kasih kepada Bapak Dr. Keni, S.E., M.M. selaku dosen pembimbing yang telah dengan sabar membimbing, mendukung, dan memberikan saran selama proses penyelesaian penelitian ini. Selain itu, penulis ingin berterima kasih kepada Bapak Dr. Hardius Usman yang telah membantu memberikan saran pada saat proses pengolahan data penelitian. Tidak lupa ucapan terima kasih penulis ucapkan kepada seluruh dosen dan karyawan 
program studi Magister Manajemen Universitas Tarumanagara Jakarta yang secara langsung dan tidak langsung telah mendukung penelitian ini hingga selesai.

\section{REFERENSI}

Adjei, MT., Noble, SM. \& Noble, CH. (2010). The Influence of C2C Communications in Online Brand Communities on Customer Purchase Behavior. Journal of the Academy Marketing Science, 38, 634-653.

Ahn, T., Ryu, S. \& Han, I. (2007). The Impact of Web Quality and Playfulness on User Acceptance of Online Retailing. Information \& Management, 44, 263-275.

Azemi, NA., Zaidi, H. \& Hussin, N. (2017). Information Quality in Organization for Better Decision-Making. International Journal of Academic Research in Business and Social Sciences, 7(12), 429-437.

Barber, NA. \& Taylor, DC. (2013). Experimental Approach to Assessing Actual Wine Purchase Behavior. International Journal of Wine Business Research, 25(3), 203-226.

Elliot, S., Li, G. \& Choi, C. (2012). Understanding Service Quality in a Virtual Travel Community Environment. Journal of Business Research, 66, 1153-1160.

Furner, CP., Racherla, P. \& Zhu, Z. (2012). Uncertainty, Trust and Purchase Intention Based on Online Product Reviews: An Introduction to a Multinational Study International. Journal of Networking and Virtual Organisations, 11(3/4), 260-276.

Ghozali, I. (2016). Aplikasi Analisis Multivariate dengan Program IBM SPSS 23. Semarang: Universitas Diponegoro.

Hennig-Thurau, T. \& Klee, A. (1997). The Impact of Customer Satisfaction and Relationship Quality on Customer Retention - A Critical Reassessment and Model Development. Psychology \& Marketing, 14(8), 737-765.

Hennig-Thurau, T., Gwinner, Kevin P. \& Gremler, DD. (2002). Understanding Relationship Marketing Outcomes: An Integration of Relational Benefits and Relationship Quality. Journal of Service Research, 4(3), 230-247.

Huang, E. (2012). Online Experiences and Virtual Goods Purchase Intention. Internet Research, 22(3), 252-274.

Kim, JU., Kim, WJ. \& Park, SC. (2010). Consumer Perceptions on Web Advertisements and Motivation Factors to Purchase in The Online Shopping. Computers in Human Behavior, 26, 1208-1222.

Kotler, P. \& Armstrong, G. (2012). Principles of Marketing (14 th ed.). New Jersey: Pearson Prentice Hall.

Lee, EJ. \& Shin SY. (2014). When Do Consumers Buy Online Product Reviews? Effects of Review Quality, Product Type, and Reviewer's Photo. Computers in Human Behavior, 31, 356-366.

Liat, CB. \& Wuan, YS. (2014). Factors Influencing Consumers' Online Purchase Intention: A Study Among University Students in Malaysia”. International Journal of Liberal Arts and Social Science, 2(8), 121-133.

Lillrank, P. (2003). New Research: The Quality of Information. International Journal of Quality \& Reliability Management, 20(6), 691-703.

Ma, S. (2017). Fast or Free Shipping Options in Online and Omni-Channel Retail? The Mediating Role of Uncertainty on Satisfaction and Purchase Intentions. The International Journal of Logistics Management, 28(4), 1099-1122. 
Miller, H. (1996). The Multiple Dimensions of Information Quality. Information Systems Management, 13(2), 79-82.

Mirabi, V., Akbariyeh, H. \& Tahmasebifard, H. (2015). A Study of Factors Affecting on Customers Purchase Intention Case Study: The Agencies of Bono Brand Tile in Tehran. Journal of Multidisciplinary Engineering Science and Technology, 2(1), 267-273.

Morry, MM., Reich, T. \& Kito, M. (2010). How Do I See You Relative to Myself? Relationship Quality as a Predictor of Self-and Partner-Enhancement Within Cross-Sex Friendships, Dating Relationships, and Marriages. The Journal of Social Psychology, 150(4), 369-392.

Palmatier, RW., Dant, RP., Grewal, D. \& Evans, KR. (2006). Factors Influencing the Effectiveness of Relationship Marketing: a Meta-Analysis. Journal of Marketing (70), 136-153.

Pavlou, PA., Liang, H. \& Xue, Y. (2007). Understanding and Mitigating Uncertainty in Online Exchange Relationships: A Principal-Agent Perspective. MIS Quarterly, 31(1), 105-136.

Rahman M., Albaity M., Isa, CR., \& Azma, N. (2018). Towards a Better Understanding of Fashion Clothing Purchase Involvement. Journal of Islamic Marketing 9(3), 544-559.

Shiu, EMK., Walsh, G., Hassan, LM. \& Shaw, D. (2011). Consumer Uncertainty, Revisited. Psychology \& Marketing, 28(6), 584-607.

Statista.com. (2018). Vendors' Market Share of Smartphone Shipments in Indonesia from 2014 to 2018. Retrieved December 3, 2018, from https://www.statista.com/statistics/516302/indonesia-smartphone-shipments-vendormarket-share/.

Tanjungsari, HK. \& Lunardy, D. (2016). Pengaruh Persepsi Nilai Pada Intensi Pembelian Produk Virtual Yang Dimediasi Oleh Kepuasan. MIX: Jurnal Ilmiah Manajemen, VI(2), 261-279.

Venkatraman, MP. (1989). Involvement and Risk. Psychology \& Marketing, 6(3), 229-247.

Wang, CY., Lee, HC., Wu, LW. \& Liu, CC. (2017). Quality Dimensions in Online Communities Influence Purchase Intentions. Management Decision, 55(9), 1984-1998.

Zhu, D.H., Chang, Y.P., \& Chang, A. (2015). Effects of Free Gifts With Purchase on Online Purchase Satisfaction: The Moderating Role of Uncertainty. Internet Research, 25(5), 690706. 